\title{
The diagnosis of acephalocystis racemose and missed abortion based on transvaginal ultrasonography and serum B-HCG monitoring.
}

\author{
Ying Peng", Dabao Wu, Ling Chen \\ Department of Obstetrics and Gynaecology, Anhui Provincial Hospital, Hefei, PR China
}

\begin{abstract}
The diagnosis of acephalocystis racemosa and missed abortion based on transvaginal ultrasonography and serum $\beta$-HCG monitoring was studied in this paper. The main contents of variance analysis were mainly introduced and at the same time, the main contents and research methods of hydatidiform mole detection and missed abortion diagnosis were also expounded. The results show that there are some disadvantages in the clinical diagnosis of serum $\beta$-HCG monitoring, However, the combination of transvaginal ultrasonography and serum $\beta$-HCG monitoring can make up for the deficiency of serum $\beta$ HCG monitoring to a large extent.
\end{abstract}

Keywords: Transvaginal ultrasound examination, $\beta$-HCG monitoring, Diagnosis of missed abortion. Accepted on May 24, 2017

\section{Introduction}

Missed abortion and hydatidiform mole (HM) are the common diseases in early pregnancy $[1,2]$. The standard time for early pregnancy is thirteen weeks before the embryo. The HM includes two types: complete hydatidiform mole (CHM) and partial hydatidiform mole (PHM) [3]. These moles are generally benign, which can be resolved through the way of the curettage or metastasis. HM associated missed abortion is a common special case of abortion, characterized by the death of embryonic tissue by overgrowth of placenta. Ultrasonic image examination can be used to carry out a comprehensive examination of the early embryos. Transvaginal ultrasound can directly scan organs. Monitoring of serum $\beta-\mathrm{HCG}$ is a key index in the confirmation of pregnancy [4]. This hormone is secreted by the placental cells during pregnancy. Based on the theories at home and abroad, the diagnosis of acephalocystis racemose and missed abortion based on transvaginal ultrasonography and serum $\beta$-HCG monitoring is analyzed and studied through the method of constructing the variance analysis model in this paper.

\section{State of the Art}

The issue of the diagnosis of acephalocystis racemose and missed abortion based on transvaginal ultrasonography and serum $\beta$-HCG monitoring is analyzed and studied by using the method of variance analysis also known as "ANOVA" or "F test". This is mainly used for the analysis and research on the controllable degree of the things with certain differences. In general, things with a certain degree of complexity include a number of factors that affect each other. Variance analysis can be used to make a significant difference analysis of these factors, and analyze the impact of the relationship among the factors. The basic principle of variance analysis is to decompose the variance of the factor and to find the sum of squares. There are certain assumptions in the variance analysis. Firstly, the samples are random; secondly, the relationship between samples is independent of each other; thirdly, there is a normal distribution relationship between samples; finally, the sample variance is consistent.

\section{Methodology}

\section{Analysis of the diagnosis of transvaginal ultrasound examination and missed abortion}

Missed abortion is one of the most serious ultrasonic manifestations during the early pregnancy. According to the statistics, most of the pregnancy tests of missed abortion patients are negative, but there are a few positive patients. The positive patients should pay attention to other complications such as hydatidiform mole, and choriocarcinomas after curettage. The sonogram of ultrasonographic missed abortion shows the following disease identifications. The delay of ovulation and the identification of early pregnancy, the atypical hydatidiform mole, cystic degeneration of uterine fibroids are the major identification symptoms [5,6]. Application of transvaginal ultrasound technology is beneficial for missed abortion patients. The results obtained by this technique can be used as the basis for diagnosis of hydatidiform mole and abnormal pregnancy [7]. This technique helps the doctors to better understand the pathological changes. In addition, the application of ultrasonic imaging technology can avoid the blindness of miscarriage or abortion in great extent. For patients with severe adhesions of the uterine wall which can't 
be cleaned once, the curettage operation can be carried out again under the guidance of transvaginal ultrasonography.

\section{Analysis model of the diagnosis of acephalocystis racemose and missed abortion based on serum $\beta$ - HCG monitoring}

Human chorionic gonadotropin (HCG) is a glycoprotein hormone secreted by trophoblast cells. It is composed of two subunits [8]. A subunit is composed of 145 amino acids, with strong antigen specificity. It is able to differentiate with the yellow stimulating hormone, follicle stimulating hormone, thyroid stimulating hormone and so on which are similar to the a-HCG chain. Therefore, the concentration of $\beta-\mathrm{HCG}$ can reflect the concentration of HCG in blood, which is of great value in the diagnosis and monitoring of early pregnancy and ectopic pregnancy [9].

The construction process of the variance analysis model is: Firstly, the formula (1) is used to carry on the factor analysis and the construction of linear statistical model; secondly, the formula (2) is used to determine the relative independence of each factor, and then the test index and influence degree are analyzed; finally, according to the formula (3), the poor processing and error verification of factors are carried out, and the data results of model analysis are obtained.
$X_{i j}=\mu+\alpha_{i}+\beta_{i}+\varepsilon_{i j} \rightarrow(1)$

$S S_{r}=\sum_{i=1}^{a} \sum_{j=1}^{b}\left(x_{i j}-\bar{x}\right)\left(x_{i j}-\bar{x}\right)^{\prime} \rightarrow(2)$

$S S_{r}=\sum_{i=1}^{k} n_{i}\left(x_{i j}-\bar{x}\right)\left(x_{i j}-\bar{x}\right)^{\prime} \rightarrow(3)$

\section{Result Analysis and Discussion}

The results obtained by the method described above are shown in the Tables 1 and 2 and Figure 1.

Table 1. Comparison of Serum B-HCG.

\begin{tabular}{|c|c|c|c|c|}
\hline Group & $\begin{array}{l}\text { The number } \\
\text { of cases }\end{array}$ & $\bar{x}+s$ & $\mathbf{F}$ & $\mathbf{P}$ \\
\hline $\begin{array}{l}\text { Normal pregnancy } \\
\text { group }\end{array}$ & 22 & $51106.94 \pm 3101.91$ & \multirow{3}{*}{14.726} & \multirow{3}{*}{$<0.001$} \\
\hline $\begin{array}{l}\text { Missed abortion } \\
\text { group }\end{array}$ & 48 & $18032.84 \pm 3466.40$ & & \\
\hline $\begin{array}{l}\text { Atypical } \\
\text { hydatidiform mole }\end{array}$ & 19 & $152260.85 \pm 8103.04$ & & \\
\hline
\end{tabular}

Table 2. Comparative analysis of the coincidencerate of diagnosis of missed abortion.

\begin{tabular}{|c|c|c|c|c|c|}
\hline Inspection method & $\begin{array}{l}\text { The number of } \\
\text { diagnosis }\end{array}$ & correct & The number of misdiagnosed cases & Total & Coincidence rate \\
\hline TVS & 70 & & 10 & 80 & 87.5 \\
\hline Serum $\beta$-HCG & 62 & & 18 & 80 & 77.5 \\
\hline The two United & 79 & & 1 & 80 & 98.75 \\
\hline
\end{tabular}

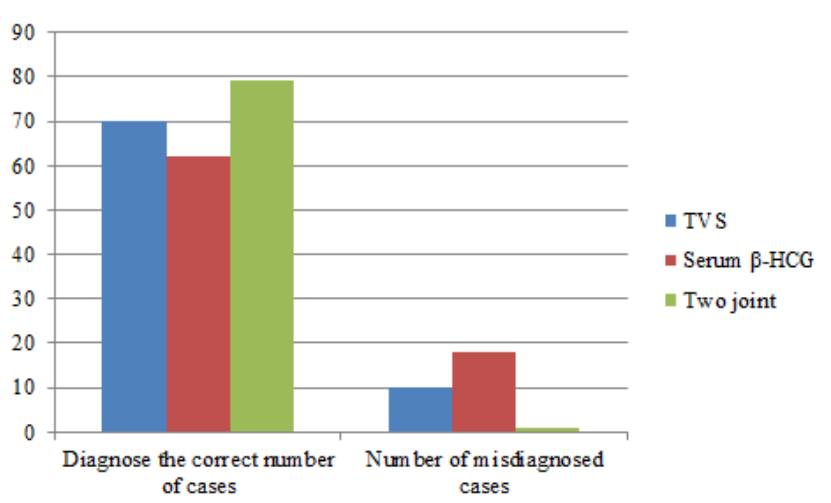

Figure 1. Comparative analysis of missed abortion diagnosis of the three methods.

\section{Discussion}

The serum $\beta$-HCG value of atypical hydatidiform mole group was significantly higher than that in normal pregnancy group and missed abortion group. The normal pregnancy group had comparatively higher $\beta-\mathrm{HCG}$ value than that of missed abortion group. The diagnostic coincidence rate of the combination of the two methods was higher than that of TVS and serum $\beta$-HCG. However, the coincidence rate of TVS method was slightly higher than that of serum $\beta$-HCG. Thus, study concluded that there are chances of false negative results in the clinical diagnosis of serum $\beta$-HCG. The main limitation of the test is frequent hormonal changes during the early pregnancy period. There are equal chances of false positive results also. However, the combination of transvaginal ultrasonography and serum $\beta$-HCG monitoring can make up for the limitations of serum $\beta$-HCG monitoring to a great extent.

Irvine et al. [10] has discussed the need of alternative diagnostic tool for the ectopic pregnancies and the authors described a case of undetected ultrasound results during missed abortion. This case had a serial change in $\beta$-HCG whereas all other evidence presentations were nill. This study has also depicted a demand for the combinational detection model.

\section{Conclusions}

With the continuous development of modern medical technology, doctors can diagnose and predict the disease 


\section{HCG monitoring}

through various technical examinations. This helps to avoid the deterioration of the disease and reduces the patient's life risk to great extent. Based on this, the issue of the diagnosis of acephalocystis racemose and missed abortion based on transvaginal ultrasonography and serum $\beta$-HCG monitoring was studied and analyzed by means of constructing variance analysis model in this paper. The study also defines the variance analysis model of acephalocystis racemose and missed abortion based on serum $\beta$-HCG monitoring. The data analysis of the results shows that combination of transvaginal ultrasonography and serum $\beta$-HCG monitoring has more efficiency compared to single detection models. The result of this research shows a favorable model to optimize the method for diagnosis of missed abortion. The authors conclude that the application of the combination of transvaginal ultrasonography and serum $\beta$-HCG monitoring can get a more accurate result of the diagnosis of hydatidiform mole and missed abortion.

\section{References}

1. Li X, Gu Y, Ren Z. Missed diagnosis and misdiagnosis of hydatidiform mole after artificial abortion. Chinese J Clinicians 2015.

2. Fowler DJ, Lindsay I, Seckl MJ, Sebire NJ. Routine preevacuation ultrasound diagnosis of hydatidiform mole: experience of more than 1000 cases from a regional referral center. Ultrasound Obstet Gynecol 2006; 27: 56-60.

3. Szulman AE, Surti U. The syndromes of hydatidiform mole: II. Morphologic evolution of the complete and partial mole. Am J Obstet Gynecol 1978; 132: 20-27.

4. Zhong ZM. Dynamic monitoring of serum progesterone and blood beta HCG in the diagnosis of missed abortion clinical significance. Chinese J Trauma Disability Med 2013.
5. Wu HL, Marwah S, Wang $\mathrm{P}$, Wang QM, Chen XW. Misoprostol for medical treatment of missed abortion: a systematic review and network meta-analysis. Sci Reprt 2017; 7: 1664.

6. Freeman MD, Porat N, Rojansky N, Elami-Suzin M, Winograd O, Ben-Meir A. Physical symptoms and emotional responses among women undergoing induced abortion protocols during the second trimester. Int $\mathrm{J}$ Gynecol Obstet 2016; 135: 154-157.

7. Knez J, Day A, Jurkovic D. Ultrasound imaging in the management of bleeding and pain in early pregnancy. Best Pract Res Clin Obstet Gynaecol 2014; 28: 621-636.

8. Ratner LD, Rulli SB, Huhtaniemi IT. Genetically modified mouse models addressing gonadotropin function. Reprod Biol 2014; 14: 9-15.

9. Barjaktarovic M, Korevaar TI, Jaddoe VW, de Rijke YB, Visser TJ, Peeters RP, Steegers EA. Human chorionic gonadotropin (hCG) concentrations during the late first trimester are associated with fetal growth in a fetal sexspecific manner. Euro J Epidemiol 2016; 5: 1-10.

10. Irvine LM, Padwick ML. Case report: Serial serum HCG measurements in a patient with an ectopic pregnancy: a case for caution. Hum Reprod 2000; 15: 1646-1647.

\section{*Correspondence to}

Ying Peng

Department of Obstetrics and Gynaecology

Anhui Provincial Hospital

PR China 